Earth \& Environment | Songmei Shi \& Xinhua He

\section{Nutrient management strategies for sustainable mulberry plantations}

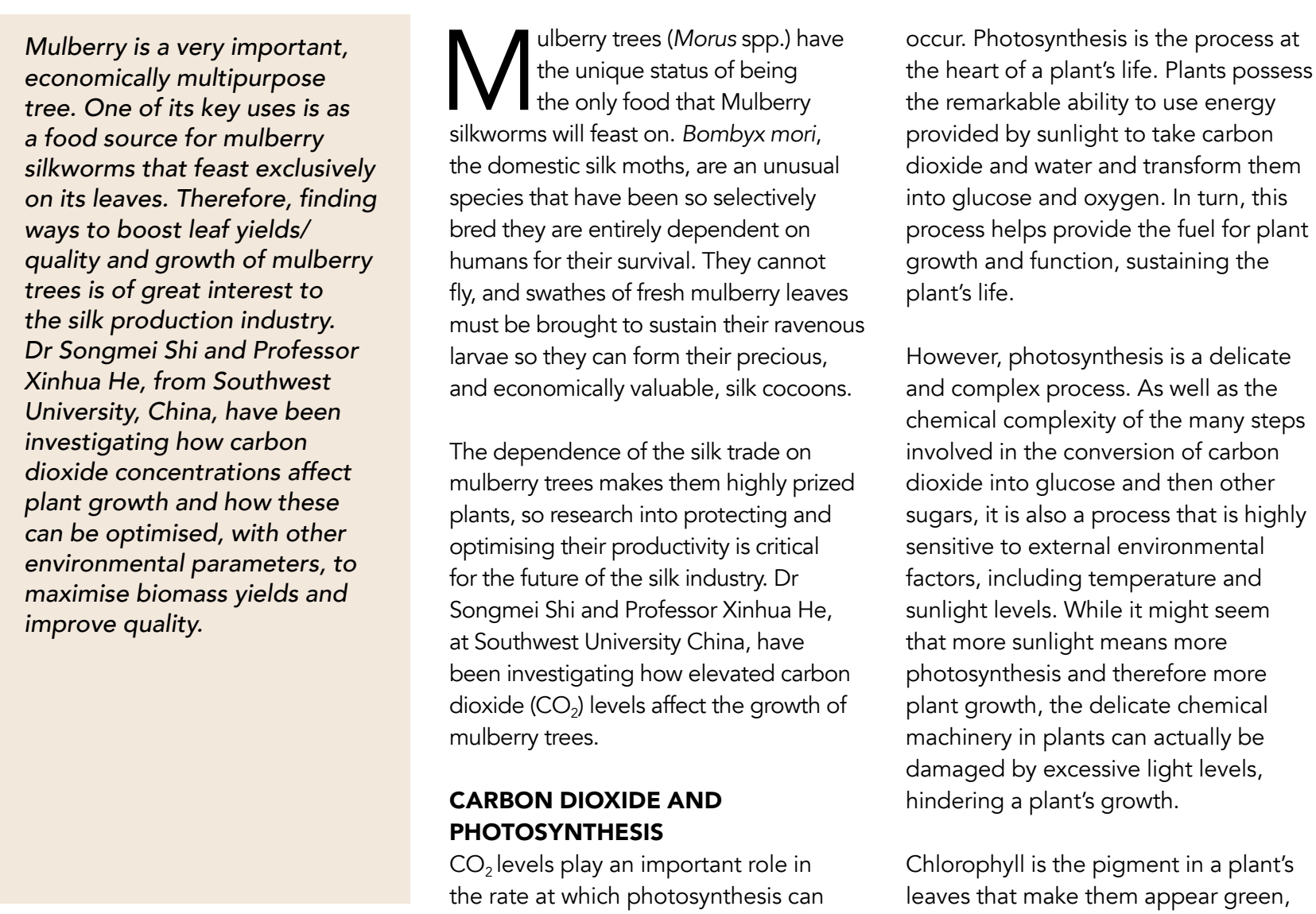

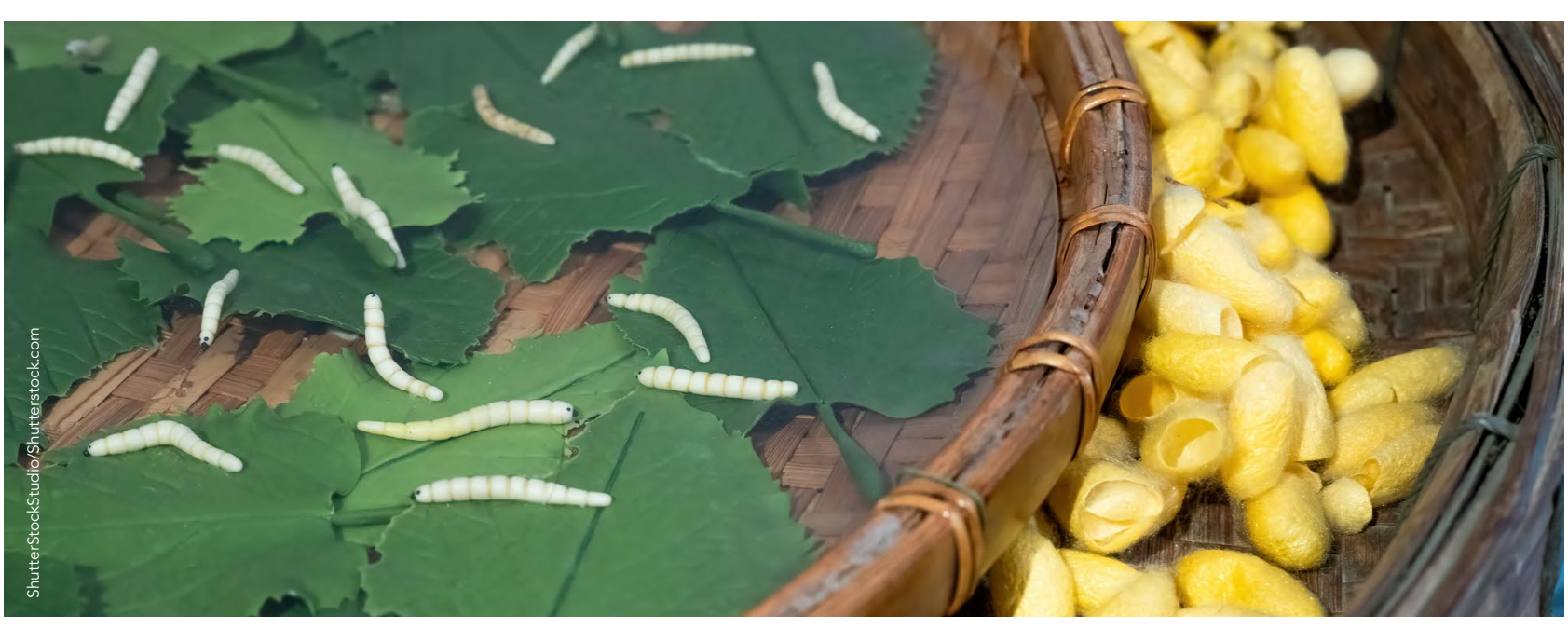

and it is the antenna that captures

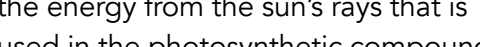
Many plants will only produce the large quantities of chlorophyll that give large their vivid green appearance during seasons with high light levels. This is why, during the autumn, leaves often turn red. This is a strategy to consen energy by limiting growth.

Elevated $\mathrm{CO}_{2}$ levels generally lead to faster photosynthesis, unless another factor, such as the light levels, is the rate-limiting step. The number of environmental variables that need to be considered and controlled to optimise photosynthesis levels for maximum biomass production is far from trivial, and finding optimal rang valuable biomass.

\section{BIOMASS PRODUCTION}

AND PLANT NUTRITION

One of the effects from increasing

be on plant growth, however the

effects of increasing atmospheric $\mathrm{CO}_{2}$

concentrations from current levels

are not well understood. Moreover,

previous studies have been performed under averaged, steady-state $\mathrm{CO}_{2}$

concentrations, so any differences

between daytime and nighttime

esponses are not revealed. Ambien $\mathrm{CO}_{2}$ can be $10-20 \%$ higher at night, $\mathrm{CO}_{2}$ concentrations due to factors $\mathrm{CO}_{2}$ concentrations due to factors such as windspeed and the shape affect the movement and exchange atmospheric gases.

Dr Shi and Professor He wanted to study the mulberry under 'real-life' conditions, and take a closer look at any differences in the way the plants responded to changes in $\mathrm{CO}_{2}$ concentrations. As well as examining changes in leaf growth, plant height and overall biomass, the researchers were interested to investigate the mineral uptake and storage of the plants. This is because the mineral levels in the leaves determine the leaf's nutrition hungry silkworms. humans or very hungry silkworms. Greater uptake of sol nutrients, lke nilrogen, phosphorous
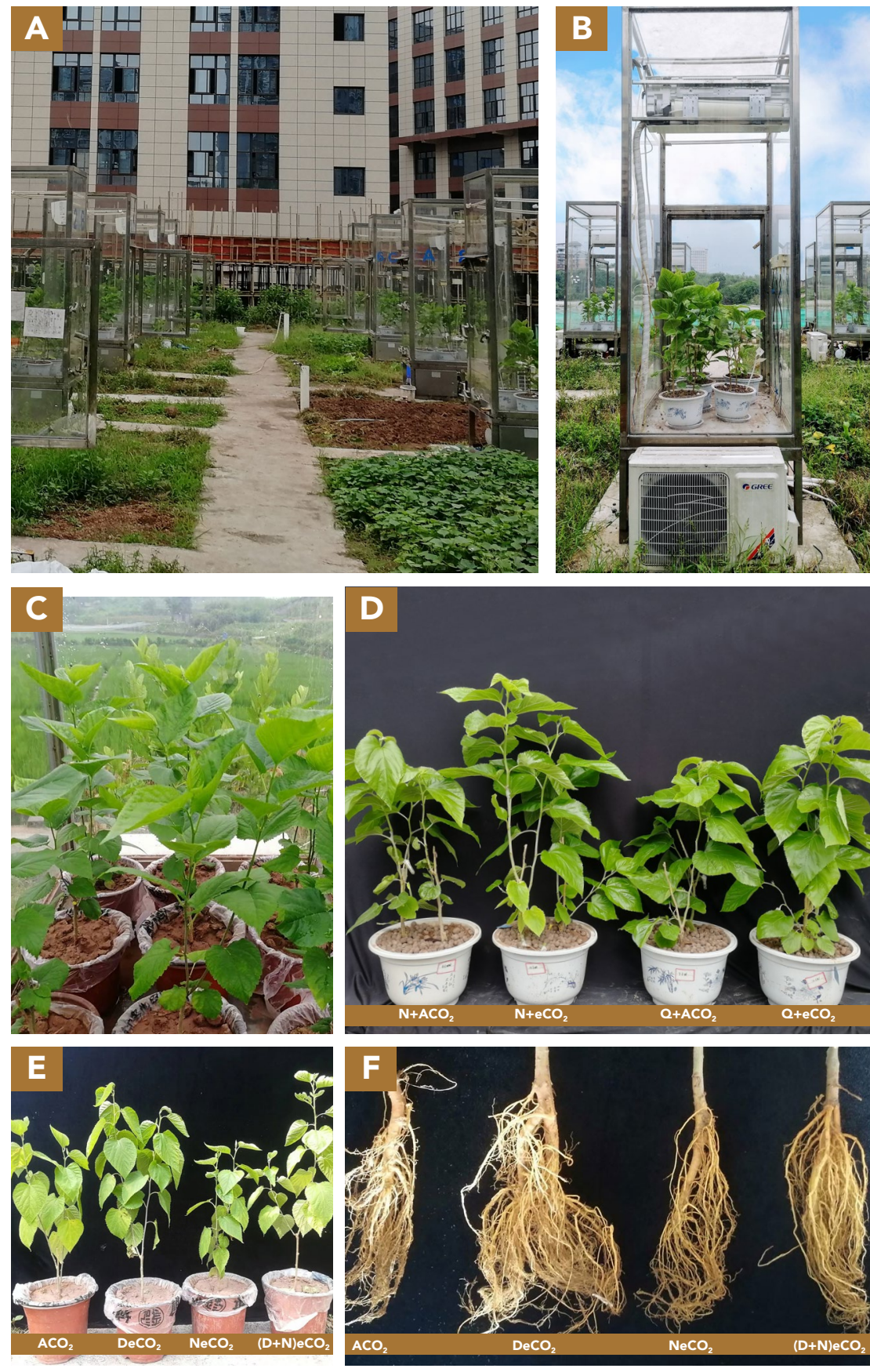

Figure 1. (A, B) Twelve environmentally controlled glass-made growth chambers were constructed
in 2016 at the National Monitoring Station of Soil Fertility and Fertilizer Efficiency on Purple Soils in Southwest University. (C) Growth statue of Morus alba var. Gui-sang-you 62 in the growth chambers. $(\mathrm{D})$ Growth of two mulberry varieties: Morus multicaulis Perr. var. Qiangsang $(\mathrm{Q})$ and
NongSang $(\mathrm{N})$ under ambient $\mathrm{CO}_{2}\left(\mathrm{ACO}_{2}\right)$ and continuous daytime and nighttime elevated $\mathrm{CO}$

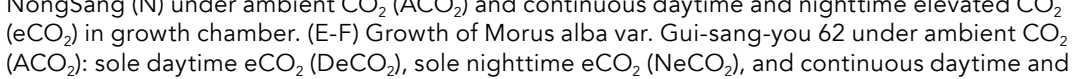

A balance between nutrition levels and carbon dioxide concentrations is key to growing large, nutritious plants.

metabolism, and if such nutrients are available in limited supply this can also

DAYTIME AND NIGHTTIME RESULTS To mimic real-life conditions, the 

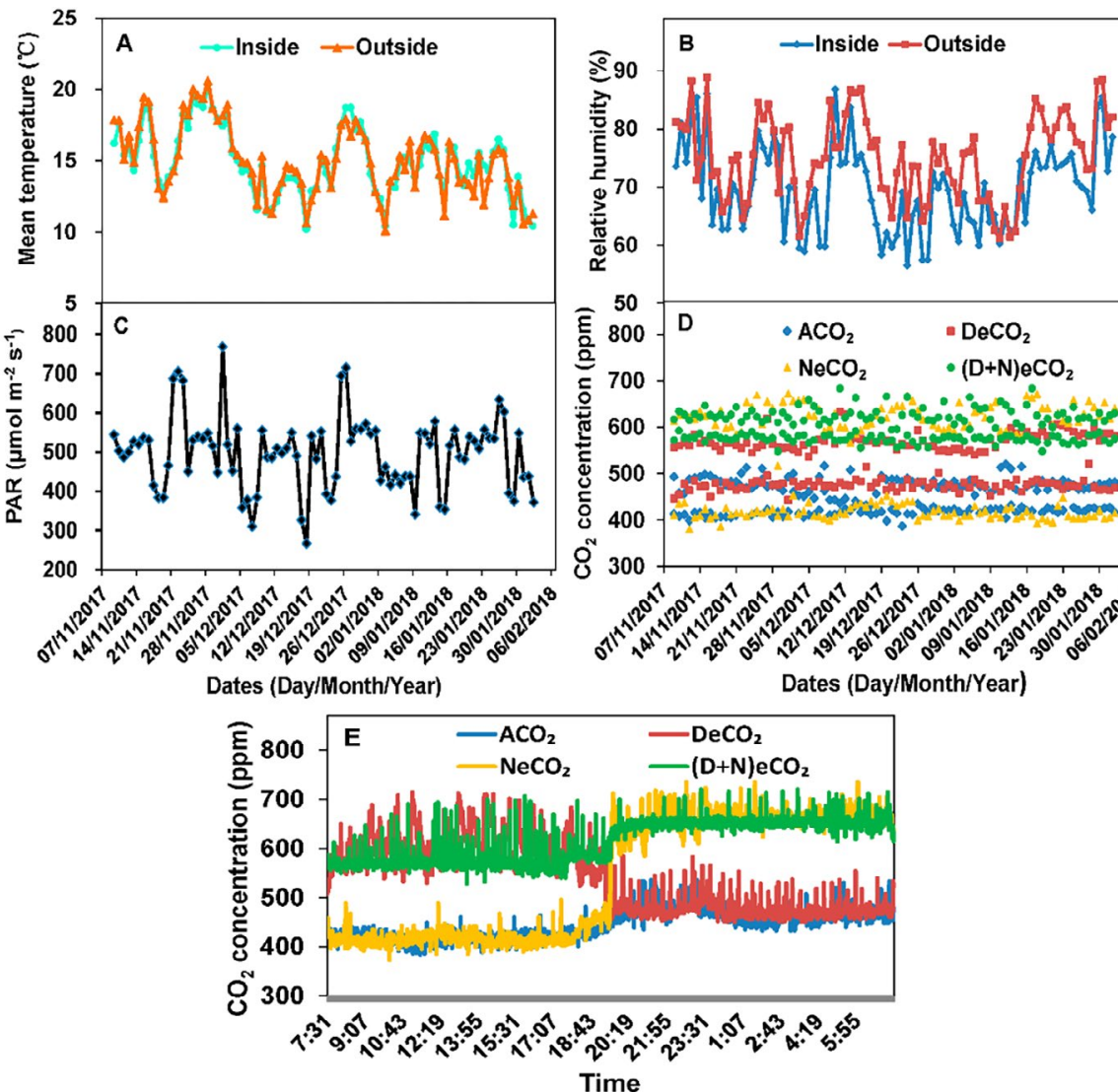

Figure 2 Mean temperature $(A)$, relative humidity (B), photosynthetic active radiation $(P A R,(C))$,
and $\mathrm{CO}_{2}$ concentration $(D, E)$ over the experimental period in the growth chambers. $A C D_{2}$ : ambienter

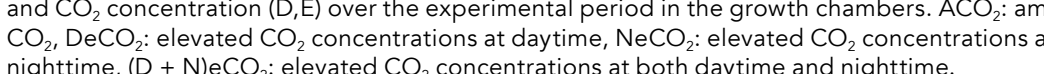

A single small silkworm might eat as much as half a kilogram of mulberry leaves before moving to the next stage in its life cycle.

old mulberry seedlings, inside environmentally controlled glass growth The chambers were all subject to the same light, temperature, humidity, and fertilisation conditions, but the concentration and time of delivery of $\mathrm{CO}_{2}$ was varied in each chamber. By precisely controlling the environmental actors in these growth chambers, the research team could be more confident that any changes they did observe were truly the result of variations in the $\mathrm{CO}_{2}$ fevels, and not from other environmental factors.

The researchers studied the effects of different $\mathrm{CO}_{2}$ concentrations in the grow houses, during both day and
night conditions. They observed that

The full effects of increased $\mathrm{CO}_{2}$ levels are more complex, however. Despite increased daytime $\mathrm{CO}_{2}$, the plants that experienced elevated $\mathrm{CO}_{2}$ level also showed reduced chlorophyl a slower photosynthetic rate. The research team suggested this may be because of the overall reduced nutrient concentrations in the plant, which in turn Another hypothesis was that growing the seedlings in pots could have led to restricted plant growth and hindered the movement of nutrients to the roots.

\section{BALANCING NUTRITION}

\section{AND CARBON DIOXIDE}

The research team's findings show that, daytime rather than nighttime, elevated $\mathrm{CO}_{2}$ improves plant growth and leaf quality of mulberry seedings, but while elevated $\mathrm{CO}_{2}$ could be a potential this needs to be balanowh production, addition of specific minerals, including Achieving a balance between nutrition levels and $\mathrm{CO}_{2}$ concentrations is the $\mathrm{key}$ to growing large, nutritious plants that can support a large silkworm population. A single small silkworm might eat as much as half a kilogram of mulberry leaves before moving to the next stage in its life cycle, so it is crucial that the trees can produce enough biomass to keep them well fed.

Dr Shi and Professor He's work has also shown that increasing $\mathrm{CO}_{2}$ levels for intensively farmed plants at night is unnecessary and so, for plants being grownin controlled atmospheric the daytime periods wher it has the most significant impact This saves unnecessary $\mathrm{CO}_{2}$ production during

farming.

Securing future food supplies using fastgrowing plants such as the mulberry, that is also used to feed livestock as well as the economically important silkworms, is a key challenge for improving the resilience of food stocks around the world. Finding approaches that can help maintain or boost the nutritional value of these plants under such changing condinions is equally as important as finding ways to encourage plant growt key for the species that deply upon the inhibit processes such as photosynthesis. nitrogen, phosphorous and magnesium on gas usage costs and also minimises

\section{Behind the Research Assanem Shi \\ E: shismei@email.swu.edu.cn I: +86 13658383482 W: www.researchgate.net/

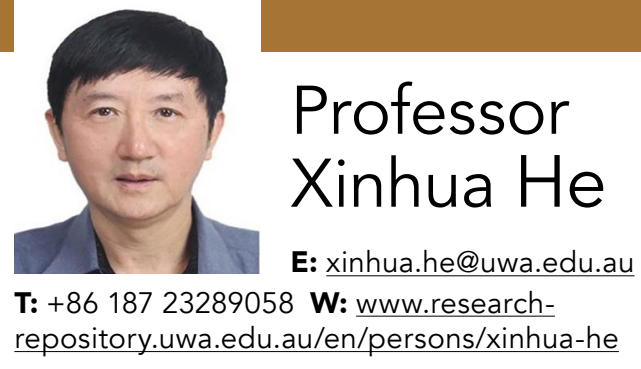

Research Objectives

The effects of environmental change on plant growth.

\section{Detail}

College of Resources and Environment Southwest University, 2 Tianshen Road, Beibei District, Chongqing

Bio Australia. Their research focuses on the responses of plant growth, yield and quality, as well as soil nutrient change.

Songmei Shi is a Post-doctoral Fellow with a PhD in agronomy, at Southwest University, China. Xinhua He has a PhD in Plant Ecophysiology from the University of Queensland, Australia, and is a Professor at Southwest University,

Funding of China (4111800096), Science and Technology Department of Sichuan Uiversity of Western of International S\&T Collaboration

\section{References}

Shi, S., Qiu, Y., Wen, M., Xu, X., Dong, X., \& Xu, C., (2021). Daytime, Not Nightime, llevated Atmospheric Carbon Mulide Exposure Imper Es Plad Growth and Leaf Quality of 11. doi.org/10.3389/fpls.2020.609031

Shi, S., Xu, X., Dong, X., Xu, C., Qiu, Y., \& He, X., (2021). Photosynthetic Acclimation and Growth Responses to Elevated $\mathrm{CO}_{2}$ Associate with Leaf Nitrogen and Phosphorus 12, 660. doi.org/10.3390/f12060660

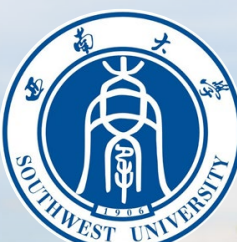

\section{Personal Response}

What other factors do you think will be important to ore to boost mulberry tree growth?

II Except $\mathrm{CO}_{2}$ and fertiliser, water is pivotal to various photochemical processes of plants such as leaf photosynthesis, which is regulated by plant water water supply could boost mulberry growth. In addition, elevated $\mathrm{CO}_{2}$ and/or temperature can quantitatively and interactively affect the synthesis and release of labile sugars, organic acids, and and the activity of rhizospheric and root-associated microbes, which may subsequently alter the nutrient
availability to plants. 